\title{
Weed Control and Grain Sorghum (Sorghum bicolor) Tolerance to Pyrasulfotole plus Bromoxynil
}

\author{
Dan D. Fromme, ${ }^{1}$ Peter A. Dotray, ${ }^{2}$ W. James Grichar, ${ }^{3}$ and Carlos J. Fernandez ${ }^{4}$ \\ ${ }^{1}$ Texas AgriLife Extension Service, Corpus Christi, TX 78406, USA \\ ${ }^{2}$ Texas AgriLife Research and Texas AgriLife Extension Service, Lubbock, TX 79403, USA \\ ${ }^{3}$ Texas AgriLife Research, Corpus Christi, TX 78102, USA \\ ${ }^{4}$ Texas AgriLife Research, Corpus Christi, TX 78406, USA \\ Correspondence should be addressed to Dan D. Fromme, d-fromme@tamu.edu
}

Received 18 July 2012; Accepted 8 October 2012

Academic Editor: David Clay

Copyright (C) 2012 Dan D. Fromme et al. This is an open access article distributed under the Creative Commons Attribution License, which permits unrestricted use, distribution, and reproduction in any medium, provided the original work is properly cited.

Field studies were conducted during the 2008 and 2009 growing seasons at five locations in the Texas grain sorghum producing regions to evaluate pyrasulfotole plus bromoxynil combinations for weed control and grain sorghum response. All pyrasulfotole plus bromoxynil combinations controlled Amaranthus palmeri, Cucumis melo, and Proboscidea louisianica at least $94 \%$ while control of Urochloa texana was never better than 69\%. Pyrasulfotole plus bromoxynil combinations did result in early season chlorosis and stunting; however, by the end of the growing season no visual injury or stunting differences were noted when compared to the untreated check. Early season grain sorghum chlorosis and stunting with pyrasulfotole plus bromoxynil combinations did not affect grain sorghum yields with the exception of pyrasulfotole at $0.03 \mathrm{~kg}$ ai $/$ ha plus bromoxynil at $0.26 \mathrm{~kg}$ ai $/$ ha plus atrazine at $0.58 \mathrm{~kg}$ ai/ha applied early postemergence followed by pyrasulfotole plus bromoxynil applied midpostemergence which reduced yield at one of two locations in 2008. Grain sorghum yield increased following all pyrasulfotole plus bromoxynil treatments compared to the untreated check in 2009.

\section{Introduction}

Weed control in grain sorghum is a challenge because of the limited number of herbicides available to growers, rotational crop restrictions following a number of herbicides registered for use in grain sorghum, and because of the increased presence of herbicide resistant weeds. Competition from broadleaf weeds reduced grain sorghum yields more than grass species competition or mixtures of broadleaf and grass weeds [1-3]; however, weed competition the first 2 wks after crop emergence has not reduced grain sorghum yields regardless of the weeds studied $[3,4]$. Duration of weed growth beyond 2 wks after grain sorghum emergence reduced yields depending on the weed species and environmental conditions [1-5]. Yield reductions primarily were due to the reduced seed/panicle [4-6], but reduced seed weight or panicles/plant also were important $[1,7]$.

Bromoxynil is a postemergence (POST) herbicide that is used for weed control in many crops and controls a broad spectrum of annual broadleaf weeds including Ipomoea spp., Sesbania exaltata (Raf.) Coryl, Chenopodium album L., Ambrosia artemisiifolia L., Sida spinosa L., and Anoda cristata L. [8-12]. It does not effectively control grass species [8] and only controls Amaranthus spp. with properly timed applications $[11,13,14]$. Bromoxynil applications may control numerous broadleaf weed; however, many weed species may not be adequately controlled [8, 10, 12-14].

Pyrasulfotole is a new herbicidal active ingredient, belonging to the bleaching class of herbicides, and its action is based on the inhibition of the enzyme 4hydroxyphenylpyruvate dioxygenase (HPPD) [15]. It controls a wide range of broadleaf weeds including Stellaria media, C. album, Solanum spp., Amaranthus spp., and Abutilon theophrasti in wheat (Triticum aestivum L.), barley (Hordeum vulgare L.), and triticale (Triticosecale spp.) [16]. Crop tolerance with pyrasulfotole is guaranteed through the inclusion of mefenpyr-diethyl, which ensures crop safety in all cereal varieties [16]. It has been suggested that 
pyrasulfotole be included in mixtures with bromoxynil and fenoxaprop to improve control of broadleaf weeds and grasses, respectively [16].

The use of pyrasulfotole plus bromoxynil combinations has been investigated in a number of crops including various cereal crops [17-19] and grain sorghum [20]. Paulsgrove et al. [17], Thorsness et al. [18], and Watteyne et al. [20] reported that this combination controlled Kochia scoparia L., Amaranthus spp., Polygonum convolvulus L., Chenopodium album L., Thlaspi arvense L., Salsola iberica Sennan \& Paul, Lactuca serriola L., and Solanum spp. They reported that the best control was achieved when this combination was applied to weeds at the 1- to 8-leaf stage and included ammonium sulfate in the mix. Geier and Stahlman [19] reported that pyrasulfotole plus bromoxynil combinations controlled Descurainia sophia L. greater than 95\% and fall applications controlled Lamium amplexicaule L. 100\%. All wheat plots treated with herbicides yielded 3020 to $3290 \mathrm{~kg} / \mathrm{ha}$ more grain than nontreated wheat. Thompson et al. [21] reported that all treatments which contained pyrasulfotole plus bromoxynil combinations controlled $A$. retroflexus L., A. palmeri L., C. album, Abutilon theophrasti L., Helianthus annuus L., and Ipomoea hederacea L. regardless of stage of application, while Brandon and Bean [22] reported that this combination controlled Amaranthus spp. $85 \%$ one week after application, but control was reduced to $61 \%$ by the end of the season.

Limited data is available on the use of pyrasulfotole plus bromoxynil combinations in the Texas grain sorghum producing regions and the weed spectrum controlled. Therefore, the objectives of this research were to determine if combinations of pyrasulfotole plus bromoxynil applied POST could control multiple broadleaf weeds and some grass species and to investigate grain sorghum tolerance to these tank-mix combinations and systems.

\section{Materials and Methods}

2.1. Field Studies. Studies were conducted during the 2008 and 2009 growing seasons at the Texas AgriLife Research site near Yoakum in south-central Texas and at the Texas AgriLife Research and Extension Center near Lubbock in the Texas High Plains, and in 2008 at the Texas AgriLife Research and Extension Center near Corpus Christi in the Coastal Bend area, to evaluate weed control and grain sorghum response to POST applications of bromoxynil plus pyrasulfotole. However, due to extremely dry conditions during the 2009 growing season at Corpus Christi, this study was not planted. Soil type near Yoakum was a Denhawken sandy loam (finesilty, carbonitic, hyperthermic Fluventic Ustochrepts) with less than $1.0 \%$ organic matter and $\mathrm{pH} 7.6$ while soil type near Corpus Christi was a Victoria clay (fine, montmorillonitic, thermic Udic Pellusterts) with less than $1.0 \%$ organic matter and $\mathrm{pH}$ 7.5. Soil type at Lubbock in 2008 was an Acuff clay loam (fine-loamy, mixed, superactive thermic Aridic Paleustolls) with less than $0.8 \%$ organic matter and $\mathrm{pH} 7.7$, while in 2009 soil type was an Olton clay loam (fine, mixed, thermic Aridic Paleustolls) with less than 1.0\% organic matter and $\mathrm{pH} 7.4$.
A randomized complete-block experimental design was used and herbicide treatments and rates were replicated three times. Plot size was two rows $(97 \mathrm{~cm}$ apart) by $9.5 \mathrm{~m}$ at Yoakum, four rows $(97 \mathrm{~cm}$ apart) by $11.1 \mathrm{~m}$ at Corpus Christi, and four rows $(102 \mathrm{~cm}$ apart) by $7.3 \mathrm{~m}$ near Lubbock. At the Lubbock location, the two middle rows per plot were sprayed and the other rows were left untreated to serve as buffers while at the Corpus Christi location all four rows were sprayed. All pyrasulfotole plus bromoxynil combinations included ammonium sulfate at $3.9 \mathrm{~kg} / 378 \mathrm{~L}$. All POST herbicides at the Corpus Christi and Yoakum locations included a crop oil concentrate (AgriDex, a blend of $83 \%$ paraffin-based petroleum oil and 17\% surfactant; Helena Chemical Company, Suite 500, 6075 Poplar Avenue, Memphis, TN 38137) at 1\% v/v while at the Lubbock locations all POST herbicides included a nonionic surfactant (R-11, 90\% alkylphenol ethoxylate, butyl alcohol dimethylpolysiloxane; Wilbur-Ellis Company, P.O. Box 16458, Fresno, CA 93755) at $0.25 \%$ v/v. Herbicides were applied in water using a CO2-pressurized backpack sprayer with TeeJet 11002 DG (Spraying Systems Company, P.O. Box 7900, North Avenue, Wheaton, IL 60188) nozzles calibrated to deliver $190 \mathrm{~L} / \mathrm{ha}$ at $180 \mathrm{kPa}$ at Yoakum, TeeJet $8003 \mathrm{XR}$ calibrated to deliver $117 \mathrm{~L} / \mathrm{ha}$ at $193 \mathrm{kPa}$ at the Corpus Christi location, and TurboTee 110015 nozzles calibrated to deliver $140 \mathrm{~L} / \mathrm{ha}$ at $207 \mathrm{kPa}$ at the Lubbock locations. In 2008, at the Yoakum and Corpus Christi locations, all plots with the exception of the untreated check received $S$-metolachlor at $1.11 \mathrm{~kg} / \mathrm{ha}$ applied preemergence. Herbicides and rates for each year are shown in Tables 1 and 2. Atrazine was used as a standard comparison in 2008 while atrazine plus bromoxynil was used as the standard in 2009.

Natural infestations of Urochloa texana (Buckl.) L. were present at the Yoakum location at the population density of 4 to 6 plants $/ \mathrm{m}^{2}$ in both years while, in 2009, Cucumis melon and $A$. palmeri were present at the density of 6 to 10 plants $/ \mathrm{m}^{2}$ and 5 to 8 plants $/ \mathrm{m}^{2}$, respectively. Natural infestations of $A$. palmeri were present at the Lubbock location at the population density of 4 to 6 plants $/ \mathrm{m}^{2}$ in both years while Proboscidea louisianica L. was present in 2008. Due to dry conditions at the Corpus Christi location in 2008, weed populations were not uniform enough to provide an accurate assessment. Desired plant heights for early postemergence (EPOST) applications were 5 to $10 \mathrm{~cm}$ tall for all weeds and grain sorghum while weed heights at the mid-postemergence (MPOST) applications were 10 to $20 \mathrm{~cm}$ tall and grain sorghum was 30 to $41 \mathrm{~cm}$ tall.

For all studies, fertilizer was applied based on the soil test recommendations provided by the Texas AgriLife Extension Service Soil and Plant Testing Laboratory. At Corpus Christi, grain sorghum hybrids were planted on a flat seedbed while at the other locations hybrids were planted on a slightly raised seedbed. The grain sorghum hybrid planted at the Corpus Christi location was DK 53-67 at 135,800 seed/ha. Pioneer 85G01 was planted at Lubbock in 2008 and DK 44-20 was planted in 2009, each at 96,800 seed/ha. At Yoakum, Pioneer 85G50 was planted in 2008 and Pioneer 84 G60 was planted in 2009, each at the rate of 197,600 seed/ha. Grain sorghum was planted on March 17, 2008 at 
TABLE 1: Weed control at Lubbock and Yoakum as influenced by pyrasulfotole plus bromoxynil combinations in 2008, 4 weeks after MPOST applications.

\begin{tabular}{|c|c|c|c|c|c|}
\hline \multirow{3}{*}{ Herbicide $^{1,2}$} & \multirow{3}{*}{$\begin{array}{c}\text { Dose } \\
\mathrm{Kg} \text { ai/ha }\end{array}$} & \multirow{3}{*}{ Timing $^{3}$} & \multicolumn{3}{|c|}{ Weed $_{\text {control }}^{4}$} \\
\hline & & & A.palmeri & U. texana & P. louisianica \\
\hline & & & & $\%$ & \\
\hline Untreated & - & - & 0 & 0 & 0 \\
\hline Pyrasulfotole (P) & 0.03 & \multirow{3}{*}{$\mathrm{EP}$} & \multirow{3}{*}{100} & \multirow{3}{*}{33} & \multirow{3}{*}{100} \\
\hline +Bromoxynil (B) & 0.20 & & & & \\
\hline +Atrazine (A) & 0.58 & & & & \\
\hline $\mathrm{P}$ & 0.04 & \multirow{3}{*}{$\mathrm{EP}$} & \multirow{3}{*}{100} & \multirow{3}{*}{23} & \multirow{3}{*}{100} \\
\hline$+\mathrm{B}$ & 0.24 & & & & \\
\hline$+\mathrm{A}$ & 0.58 & & & & \\
\hline $\mathrm{P}$ & 0.03 & \multirow{4}{*}{$\mathrm{EP}$} & \multirow{4}{*}{100} & \multirow{4}{*}{33} & \multirow{4}{*}{100} \\
\hline$+\mathrm{B}$ & 0.20 & & & & \\
\hline$+\mathrm{A}$ & 0.58 & & & & \\
\hline$+2,4-\mathrm{D}$ & 0.27 & & & & \\
\hline $\mathrm{P}$ & 0.03 & \multirow{4}{*}{$\mathrm{EP}$} & \multirow{4}{*}{100} & \multirow{4}{*}{33} & \multirow{4}{*}{100} \\
\hline$+\mathrm{B}$ & 0.20 & & & & \\
\hline$+\mathrm{A}$ & 0.58 & & & & \\
\hline+ dicamba & 0.13 & & & & \\
\hline Atrazine & 0.58 & $\mathrm{EP}$ & 98 & 20 & 100 \\
\hline $\mathrm{P}$ & 0.03 & \multirow{3}{*}{ MP } & \multirow{3}{*}{100} & \multirow{3}{*}{47} & \multirow{3}{*}{100} \\
\hline$+\mathrm{B}$ & 0.20 & & & & \\
\hline$+\mathrm{A}$ & 0.58 & & & & \\
\hline $\mathrm{P}$ & 0.04 & \multirow{3}{*}{ MP } & & & \\
\hline$+\mathrm{B}$ & 0.24 & & 100 & 50 & 100 \\
\hline$+\mathrm{A}$ & 0.58 & & & & \\
\hline $\mathrm{P}$ & 0.03 & & & & \\
\hline$+\mathrm{B}$ & 0.20 & MP & 100 & 33 & 100 \\
\hline$+\mathrm{A}$ & 0.58 & & & & \\
\hline$+2,4-\mathrm{D}$ & 0.27 & & & & \\
\hline $\mathrm{P}$ & 0.03 & & & & \\
\hline$+\mathrm{B}$ & 0.20 & MP & 100 & 55 & 100 \\
\hline$+\mathrm{A}$ & 0.58 & & & & \\
\hline +dicamba & 0.13 & & & & \\
\hline Atrazine & 0.58 & MP & 100 & 30 & 100 \\
\hline $\mathrm{P}$ & 0.03 & & & & \\
\hline$+\mathrm{B}$ & 0.18 & $\mathrm{EP}+\mathrm{MP}$ & 100 & 45 & 100 \\
\hline$+\mathrm{A}$ & 0.58 & & & & \\
\hline $\mathrm{P}$ & 0.03 & & & & \\
\hline$+B$ & 0.21 & $\mathrm{EP}$ & & & \\
\hline$+\mathrm{A}$ & 0.58 & & 100 & 47 & 100 \\
\hline $\mathrm{P}$ & 0.03 & MP & & & \\
\hline$+\mathrm{B}$ & 0.18 & & & & \\
\hline
\end{tabular}


TABle 1: Continued.

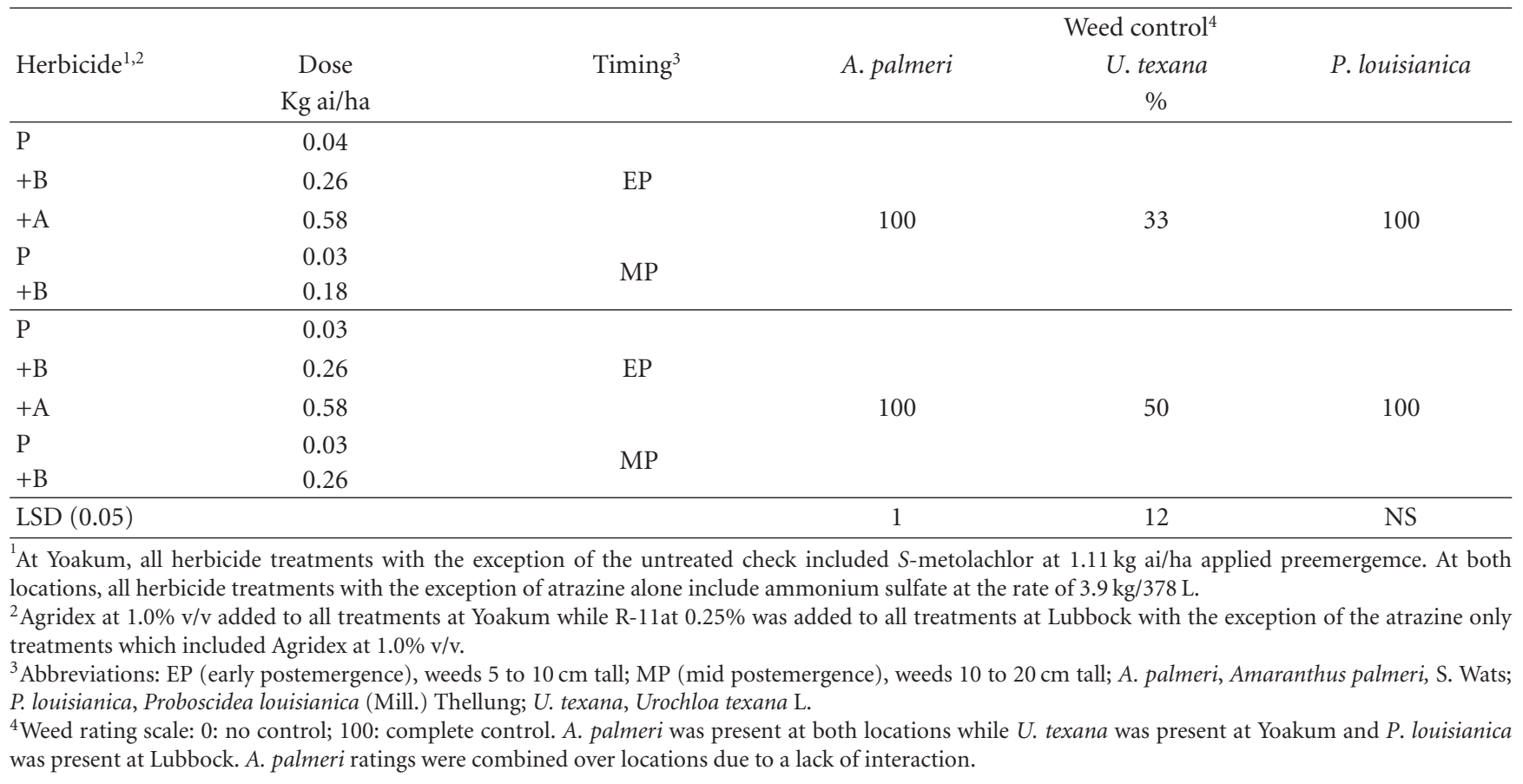

the Corpus Christi location, May 22, 2008, and May 21, 2009 at the Lubbock locations, and March 27, 2008 and April 2, 2009 at the Yoakum locations. Visual grain sorghum injury (chlorosis and stunting) due to POST herbicides was evaluated based on a scale of 0 (no chlorosis or stunting) to 100 (complete plant death). Visual weed control ratings were based on a similar scale with 0 (no control) to 100 (complete weed control). Chlorosis and stunting observations were recorded approximately $10 \mathrm{~d}$ after herbicide application while weed control ratings were taken approximately 4 weeks after MPOST applications. A final observation of herbicide stunting was taken prior to harvest.

All sites were maintained under rain-fed conditions with the exception of the Yoakum location in 2009 which received supplemental irrigation $(50.8 \mathrm{~mm})$ for the first $60 \mathrm{~d}$ after planting and the 2009 location near Lubbock which was located under a center-pivot irrigation system and received $341 \mathrm{~mm}$ of irrigation during the growing season. Rainfall was below normal for both 2008 and 2009 with above normal temperatures at all locations [23]. Rainfall during the growing season was $145.5 \mathrm{~mm}$ at Yoakum in 2008 and $275.6 \mathrm{~mm}$ in 2009; at Corpus Christi in 2008, $160 \mathrm{~mm}$ was received; and at the Lubbock locations, $436.4 \mathrm{~mm}$ was received in 2008 and $393.7 \mathrm{~mm}$ in 2009 .

2.2. Plot Harvest and Statistical Analysis. Crop yield was determined by harvesting plots with a small plot combine and crop weights were adjusted to $14 \%$ moisture. Data for grain sorghum chlorosis, stunting, and percentage of weed control were transformed to the arcsine square root prior to analysis; however, nontransformed means are presented because arcsine transformation did not affect interpretation of the data. Data were subjected to ANOVA and treatment means were separated using Fisher's Protected LSD at $P<$ 0.05. The untreated check was used for yield calculation comparison and a visual comparison for grain sorghum chlorosis and stunting and weed control and was only included in yield data analysis.

\section{Results and Discussion}

No attempt was made to combine data over years due to different treatments in both years. Data were not combined over locations, with the exception of A. palmeri data in 2008 and 2009 , due to a treatment by location interaction for grain sorghum chlorosis, stunting, and yield.

3.1. Weed Control. Weed control was recorded approximately one month after MPOST applications. In 2008, control of $A$. palmeri and P. louisianica was $100 \%$ for all pyrasulfotole plus bromoxynil treatments (Table 1). This was as good as or better than atrazine alone applied EPOST, which controlled A. palmeri $98 \%$ and P. louisianica $100 \%$. U. texana control was poor with all pyrasulfotole plus bromoxynil combinations and control was no greater than $55 \%$ at any rate or application timing while atrazine alone controlled $U$. texana 20 and 30\% with EPOST and MPOST applications, respectively. The MPOST applications of pyrasulfotole plus bromoxynil combinations did provide slightly better control of $U$. texana than EPOST applications.

In 2009, all EPOST treatments of pyrasulfotole plus bromoxynil controlled A. palmeri $100 \%$ and atrazine plus bromoxynil also provided $100 \%$ control (Table 2). The MPOST applications of pyrasulfotole plus bromoxynil controlled $A$. palmeri at least $94 \%$ while atrazine plus bromoxynil applied MPOST provided 77\% control. Amaranthus spp. are among 
TABLE 2: Weed control at Lubbock and Yoakum as influenced by pyrasulfotole plus bromoxynil combinations in 2009, 4 weeks after MPOST applications.

\begin{tabular}{|c|c|c|c|c|c|}
\hline \multirow{3}{*}{ Herbicide $^{1,2}$} & \multirow{3}{*}{$\begin{array}{c}\text { Dose } \\
\text { Kg ai/ha }\end{array}$} & \multirow{3}{*}{ Timing $^{3}$} & \multicolumn{3}{|c|}{ Weed control ${ }^{4,5}$} \\
\hline & & & A. palmeri & U. texana & C. melo \\
\hline & & & & $\%$ & \\
\hline Untreated & - & - & 0 & 0 & 0 \\
\hline Pyrasulfotole (P) & 0.03 & \multirow{3}{*}{$\mathrm{EP}$} & \multirow{3}{*}{100} & \multirow{3}{*}{64} & \multirow{3}{*}{100} \\
\hline +Bromoxynil (B) & 0.20 & & & & \\
\hline+ Atrazine $(\mathrm{A})$ & 0.58 & & & & \\
\hline $\mathrm{P}$ & 0.04 & \multirow{3}{*}{$\mathrm{EP}$} & \multirow{3}{*}{100} & \multirow{3}{*}{66} & \multirow{3}{*}{100} \\
\hline$+\mathrm{B}$ & 0.25 & & & & \\
\hline$+\mathrm{A}$ & 0.58 & & & & \\
\hline $\mathrm{P}$ & 0.03 & \multirow{4}{*}{$\mathrm{EP}$} & \multirow{4}{*}{100} & \multirow{4}{*}{69} & \multirow{4}{*}{100} \\
\hline$+\mathrm{B}$ & 0.20 & & & & \\
\hline$+\mathrm{A}$ & 0.58 & & & & \\
\hline +2,4-D Amine & 0.22 & & & & \\
\hline $\mathrm{P}$ & 0.03 & \multirow{4}{*}{$\mathrm{EP}$} & \multirow{4}{*}{100} & \multirow{4}{*}{59} & \multirow{4}{*}{100} \\
\hline$+\mathrm{B}$ & 0.20 & & & & \\
\hline$+\mathrm{A}$ & 0.58 & & & & \\
\hline +dicamba & 0.13 & & & & \\
\hline Atrazine & 0.58 & \multirow{2}{*}{$\mathrm{EP}$} & \multirow{2}{*}{100} & \multirow{2}{*}{66} & \multirow{2}{*}{100} \\
\hline +bromoxynil & 0.21 & & & & \\
\hline $\mathrm{P}$ & 0.03 & \multirow{3}{*}{ MP } & \multirow{3}{*}{100} & & \\
\hline$+\mathrm{B}$ & 0.20 & & & 54 & 100 \\
\hline$+\mathrm{A}$ & 0.58 & & & & \\
\hline $\mathrm{P}$ & 0.04 & & & & \\
\hline$+\mathrm{B}$ & 0.25 & MP & 94 & 43 & 100 \\
\hline$+\mathrm{A}$ & 0.58 & & & & \\
\hline $\mathrm{P}$ & 0.03 & & & & \\
\hline$+\mathrm{B}$ & 0.20 & MP & 100 & 58 & 100 \\
\hline$+\mathrm{A}$ & 0.58 & & & & \\
\hline +2,4 Amine & 0.22 & & & & \\
\hline $\mathrm{P}$ & 0.03 & & & & \\
\hline$+\mathrm{B}$ & 0.20 & MP & 100 & 38 & 100 \\
\hline$+\mathrm{A}$ & 0.58 & 1 VII & 100 & Jo & \\
\hline +dicamba & 0.13 & & & & \\
\hline Atrazine & 0.58 & MP & 77 & 69 & 100 \\
\hline +bromoxynil & 0.21 & & & & \\
\hline $\mathrm{P}$ & 0.03 & & & & \\
\hline$+\mathrm{B}$ & 0.20 & $\mathrm{EP}+\mathrm{MP}$ & 100 & 68 & 100 \\
\hline$+\mathrm{A}$ & 0.58 & & & & \\
\hline $\operatorname{LSD}(0.05)$ & & & 13 & 18 & NS \\
\hline
\end{tabular}

${ }^{1}$ All herbicide treatments with the exception of atrazine + bromoxynil included ammonium sulfate at the rate of $3.9 \mathrm{~kg} / 378 \mathrm{~L}$.

${ }^{2}$ Agridex at $1.0 \% \mathrm{v} / \mathrm{v}$ added to all treatments at Yoakum while R-11 at $0.25 \%$ was added to all treatments at Lubbock.

${ }^{3}$ Abbreviations: EP (early postemergence), weeds 5 to $10 \mathrm{~cm}$ tall; MP (mid postemergence), weeds 10 to $20 \mathrm{~cm}$ tall. A. palmeri, Amaranthus palmeri S. Wats;

U. texana., Urochloa texana (Buckl.) L.; C. melo., Cucumis melo L.

${ }^{4}$ Rating scale (\% weed control), 0: no control, 100: complete control.

${ }^{5}$ All weeds present at Yoakum while A. palmeri was present at Lubbock. A. palmeri ratings combined over locations due to a lack of interaction. 
the ten most common and ten most troublesome weeds in grain sorghum in 12 southern states including Puerto Rico [24]. In Texas, Amaranthus spp. ranks as the most common and troublesome weed in grain sorghum [24]. Moore and Murray [25] reported that grain sorghum yields decreased $97 \mathrm{~kg} / \mathrm{ha}$ for each increase of one A. palmeri plant per $15 \mathrm{~m}$ of row and decreased $392 \mathrm{~kg} / \mathrm{ha}$ for each increase of $1 \mathrm{~kg}$ of dry matter of the weed per $15 \mathrm{~m}$ of row. Shipley and Wiese [26] reported that one Amaranthus plant per $30 \mathrm{~cm}^{2}$ of row in irrigated grain sorghum reduced grain yield approximately $48 \%$. U. texana control with pyrasulfotole plus bromoxynil combinations or atrazine plus bromoxynil was no greater than $69 \%$ with any application timing (Table 2). C. melo control with pyrasulfotole plus bromoxynil or atrazine plus bromoxynil was $100 \%$ regardless of application timing.

3.2. Grain Sorghum Chlorosis. In 2008 at Corpus Christi, grain sorghum chlorosis was present with EPOST and EPOST plus MPOST applications of pyrasulfotole plus bromoxynil but not MPOST only applications (Table 3). All EPOST and EPOST plus MPOST applications of pyrasulfotole plus bromoxynil resulted in greater chlorosis than atrazine alone applied either EPOST or MPOST. The greatest chlorosis was noted with pyrasulfotole at $0.03 \mathrm{~kg}$ ai $/$ ha plus bromoxynil at $0.26 \mathrm{~kg}$ ai $/$ ha applied EPOST and MPOST (Table 3). At Yoakum, all pyrasulfotole plus bromoxynil combinations, with the exception of pyrasulfotole at $0.03 \mathrm{~kg} / \mathrm{ha}$ plus bromoxynil at $0.2 \mathrm{~kg}$ ai $/$ ha plus atrazine at $0.58 \mathrm{~kg}$ ai $/ \mathrm{ha}$ applied EPOST or the four-way combination of pyrasulfotole at $0.03 \mathrm{~kg} /$ ha plus bromoxynil at $0.2 \mathrm{~kg} / \mathrm{ha}$ plus atrazine at $0.58 \mathrm{~kg} / \mathrm{ha}$ plus either dicamba or 2,4-DB applied MPOST resulted in chlorosis that was greater than atrazine alone. At Lubbock, all pyrasulfotole plus bromoxynil combinations resulted in greater chlorosis than atrazine alone applied EPOST (Table 3 ).

In 2009 at Yoakum, chlorosis was 5\% or less with EPOST applications of pyrasulfotole at $0.03 \mathrm{~kg} / \mathrm{ha}$ plus bromoxynil at $0.2 \mathrm{~kg} / \mathrm{ha}$ plus atrazine at $0.58 \mathrm{~kg} / \mathrm{ha}$ plus either $2,4-$ $\mathrm{D}$ or dicamba, and atrazine plus bromoxynil while only the MPOST application of pyrasulfotole at $0.03 \mathrm{~kg} / \mathrm{ha}$ plus bromoxynil at $0.2 \mathrm{~kg} / \mathrm{ha}$ plus atrazine at $0.58 \mathrm{~kg} / \mathrm{ha}$ plus dicamba resulted in grain in grain sorghum chlorosis which was not different than the untreated check (Table 4). At Lubbock, all EPOST applications with the exception of pyrasulfotole at $0.04 \mathrm{~kg}$ ai $/$ ha plus bromoxynil at $0.25 \mathrm{~kg}$ ai $/ \mathrm{ha}$ plus atrazine at $0.58 \mathrm{~kg} /$ ha resulted in $5 \%$ or less chlorosis. All MPOST applications caused at least $12 \%$ chlorosis with less chlorosis with pyrasulfotole plus bromoxynil combinations that include either 2,4-D or dicamba (Table 4).

Other studies have noted crop chlorosis and injury with pyrasulfotole plus bromoxynil combinations. Thompson et al. [21] found that sorghum injury (they did not state the type of injury) ranged from 0 to $24 \% 5$ to 9 days after herbicide application. They reported that the addition of 2,4-D amine or dicamba to pyrasulfotole plus bromoxynil combinations reduced sorghum injury 4 to $5 \%$ compared to pyrasulfotole plus bromoxynil treatment alone. However, Brandon and Bean [22] reported increased injury with greater rates of pyrasulfotole plus bromoxynil or when atrazine or dicamba was added. Geier and Stahlman [19] noted that wheat chlorosis was generally greater with fall applications of pyrasulfotole plus bromoxynil compared to spring applied. However, this had no effect on wheat maturity or yield as pyrasulfotole plus bromoxynil-treated wheat matured one day earlier than nontreated wheat and the pyrasulfotole plus bromoxynil treated wheat yielded over $3000 \mathrm{~kg} /$ ha more than nontreated wheat.

3.3. Grain Sorghum Stunting. Grain sorghum stunting was evident early season; however, by the end of the growing season the grain sorghum had outgrown any early season injury and there were no noticeable differences (data not shown). In 2008, no noticeable stunting was noted at Corpus Christi (data not shown) while at Yoakum, pyrasulfotole at $0.03 \mathrm{~kg} / \mathrm{ha}$ plus bromoxynil at $0.2 \mathrm{~kg} / \mathrm{ha}$ plus atrazine at $0.58 \mathrm{~kg} / \mathrm{ha}$ applied MPOST or pyrasulfotole at $0.03 \mathrm{~kg} / \mathrm{ha}$ plus bromoxynil at $0.26 \mathrm{~kg} / \mathrm{ha}$ plus atrazine at $0.58 \mathrm{~kg} / \mathrm{ha}$ applied EPOST followed by pyrasulfotole plus bromoxynil applied MPOST resulted in stunting that was greater than $20 \%$ (Table 3 ). No other herbicide treatments resulted in stunting that was greater than the untreated check. At Lubbock, atrazine applied MPOST resulted in 4\% grain sorghum stunting and only the pyrasulfotole plus bromoxynil treatment that included 2,4-D applied EPOST or MPOST resulted in grain sorghum stunting that was greater than atrazine.

In 2009 at Yoakum, stunting was greatest with pyrasulfotole plus bromoxynil treatment which included dicamba applied EPOST or two applications of pyrasulfotole plus bromoxynil plus atrazine applied EPOST plus MPOST (Table 4). At Lubbock, the greatest stunting was noted with pyrasulfotole plus bromoxynil plus atrazine plus 2,4$\mathrm{D}$ applied EPOST and the two applications of pyrasulfotole plus bromoxynil plus atrazine applied EPOST and MPOST.

3.4. Grain Sorghum Yield. Due to dry conditions at Lubbock in 2008 and Yoakum in 2009 no attempt was made to harvest the grain sorghum and in 2008 at Yoakum, yields were extremely low due to the drought conditions [23]. In 2008 at Yoakum, pyrasulfotole plus bromoxynil plus atrazine plus 2,4-D applied MPOST and pyrasulfotole pyrasulfotole at $0.03 \mathrm{~kg} / \mathrm{ha}$ plus bromoxynil at $0.26 \mathrm{~kg} / \mathrm{ha}$ plus atrazine at $0.58 \mathrm{~kg} / \mathrm{ha}$ applied EPOST followed by pyrasulfotole at $0.03 \mathrm{~kg} / \mathrm{ha}$ plus bromoxynil at $0.26 \mathrm{~kg} / \mathrm{ha}$ applied MPOST treatment resulted in grain sorghum yields that were lower than the untreated check while at Corpus Christi there were no differences in yields (Table 3). In 2009 near Lubbock, all herbicide treatments, with the exception of pyrasulfotole at $0.03 \mathrm{~kg} / \mathrm{ha}$ plus bromoxynil at $0.2 \mathrm{~kg} / \mathrm{ha}$ plus atrazine at $0.58 \mathrm{~kg} /$ ha plus $2,4-\mathrm{D}$ at $0.22 \mathrm{~kg} / \mathrm{ha}$, increased grain sorghum yields over the untreated check (Table 4). The EPOST plus MPOST application of pyrasulfotole plus bromoxynil plus atrazine produced the greatest yield. Early season grain sorghum chlorosis and stunting did not have any effect on yield as the grain sorghum quickly recovered. 


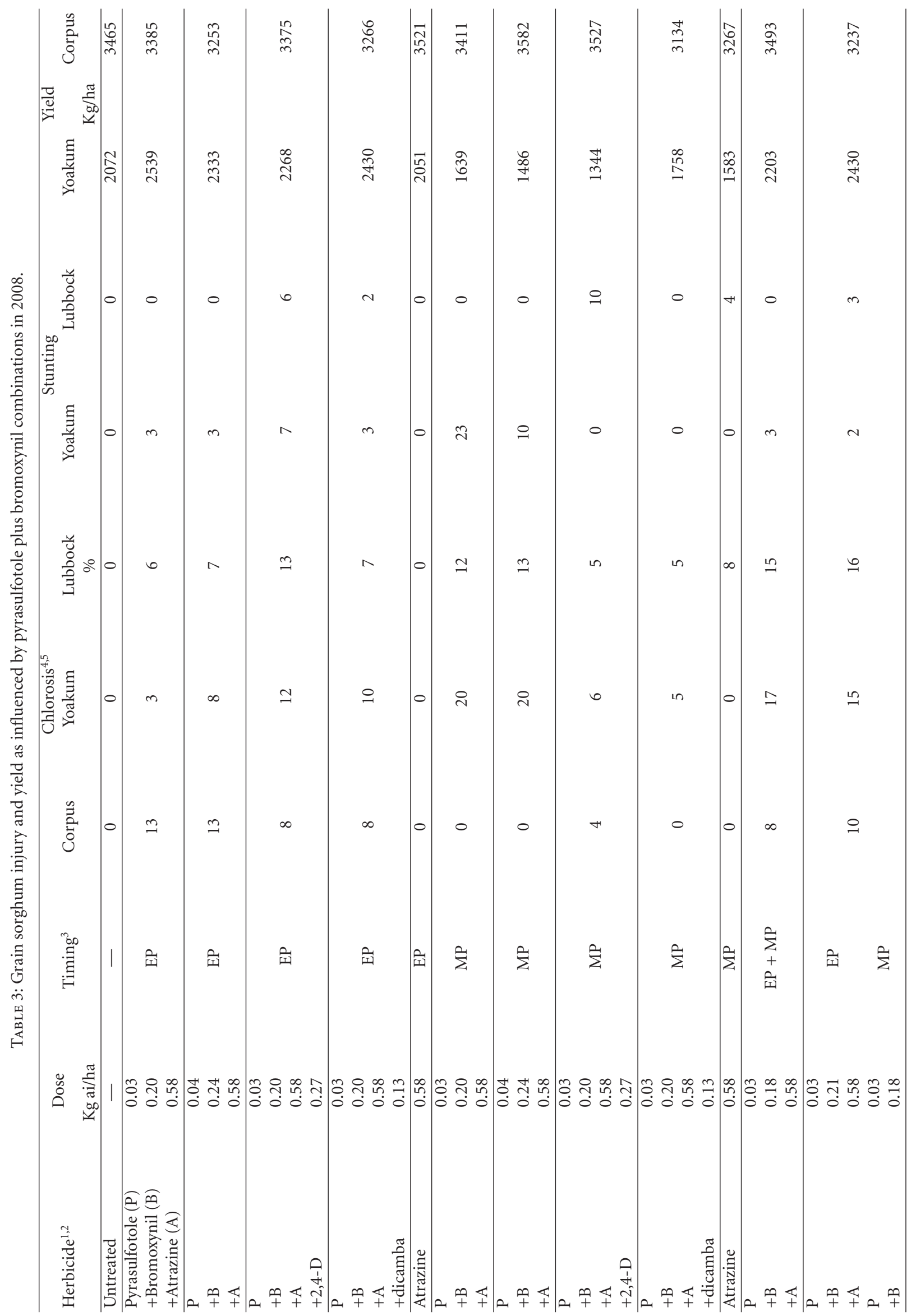




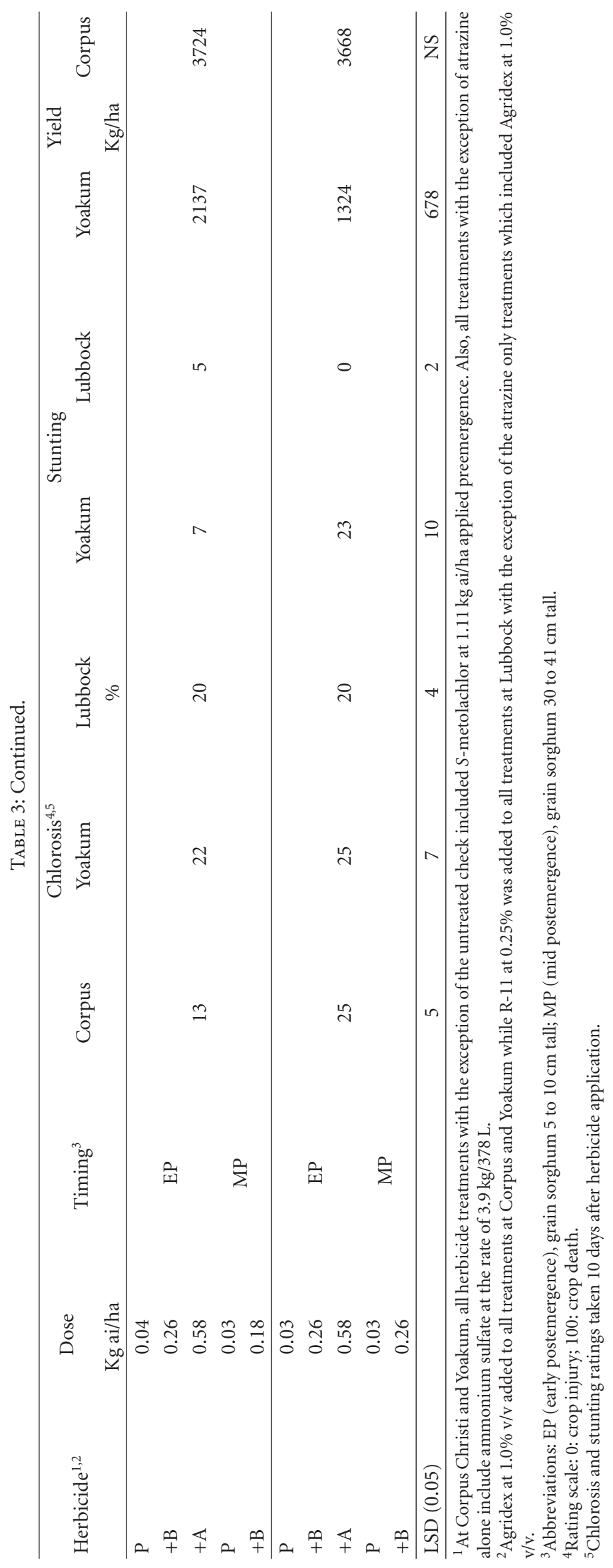




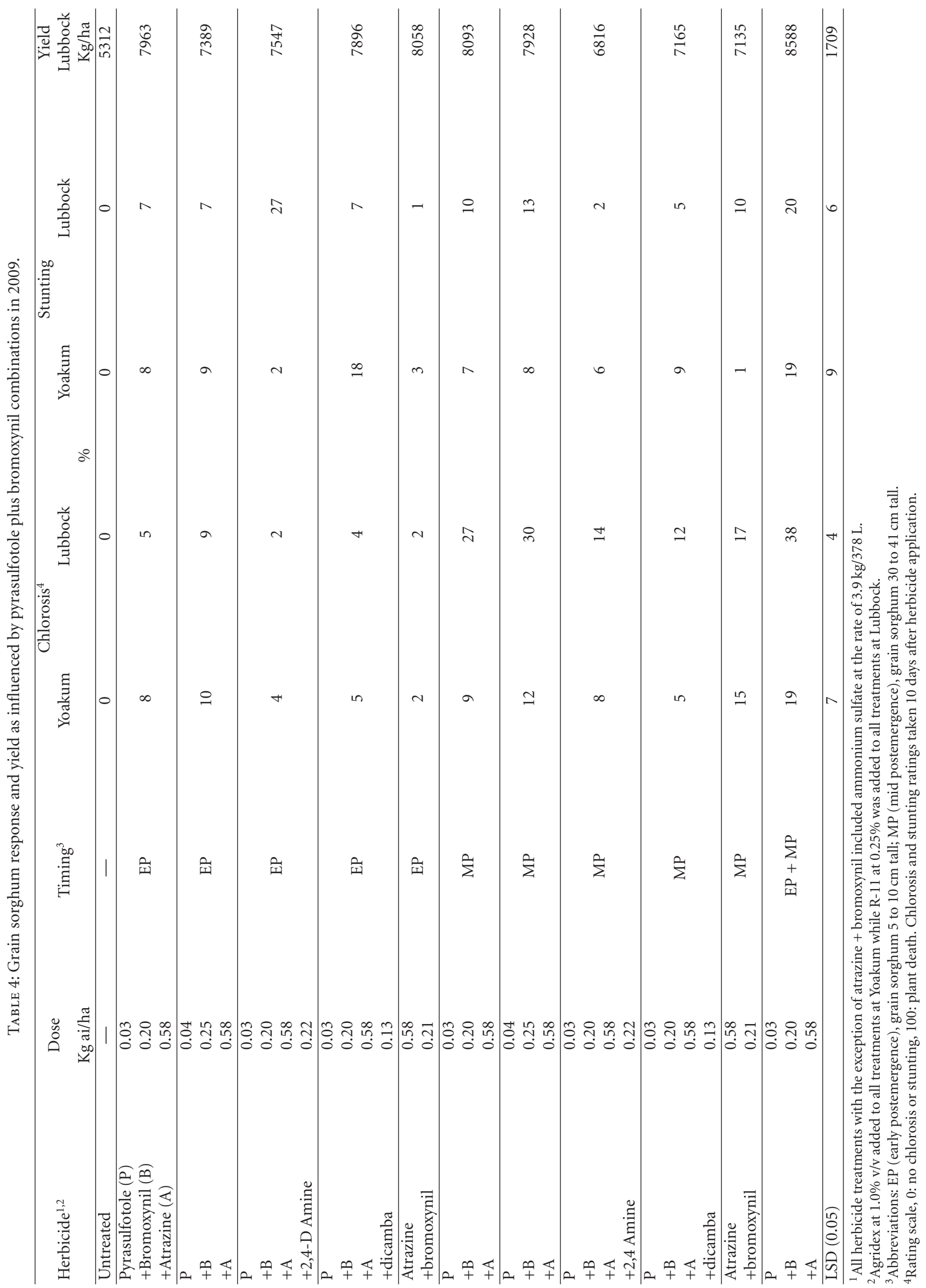




\section{Conclusions}

The results of these studies indicate that grain sorghum has adequate tolerance to pyrasulfotole plus bromoxynil combinations and although grain sorghum chlorosis and stunting was evident early in the growing season, the grain sorghum quickly grew out of it and this did not result in yield reductions. Excellent control of several problem weeds is an indication of the enhanced value this herbicide combination can bring to a weed control program in grain sorghum. Thorsness et al. [18] also noted that pyrasulfotole plus bromoxynil inhibited second flushes of select weeds including A. retroflexus L., Kochia scoparia L., and Chenopodium album L. Also, since pyrasulfotole plus bromoxynil has an excellent crop rotation profile, this makes it an attractive herbicide to use in grain sorghum.

\section{References}

[1] K. C. Feltner, H. R. Hurst, and L. E. Anderson, "Tall waterhemp competition in grain sorghum," Weed Science, vol. 17, pp. 214-216, 1969.

[2] K. C. Feltner, H. R. Hurst, and L. E. Anderson, "Yellow foxtail competiton in grain sorghum," Weed Science, vol. 17, pp. 211213, 1969.

[3] O. C. Burnside and G. A. Wicks, "The effect of weed removal treatments on sorghum growth," Weeds, vol. 15, pp. 204-207, 1967.

[4] O. C. Burnside and G. A. Wicks, "Influence of weed competition on sorghum growth," Weed Science, vol. 17, pp. 332-334, 1969.

[5] B. S. Smith, D. S. Murray, J. D. Green, W. M. Wanyahaya, and D. L. Weeks, "Interference of three annual grasses with grain sorghum (Sorghum bicolor)," Weed Technology, vol. 4, pp. 245249, 1990.

[6] J. L. Shipley and A. F. Wiese, "Economics of weed control in sorghum and wheat," Texas Agricultural Experiment Station Progress Report MP-909, 1969.

[7] J. F. Vesecky, K. C. Feltner, and R. L. Vanderlip, "Wild cane and forage sorghum competition in grain sorghum," Weed Science, vol. 21, pp. 28-32, 1973.

[8] A. S. Culpepper and A. C. York, "Weed management in no-tillage bromoxynil-tolerant cotton (Gossypium hirsutum)," Weed Technology, vol. 11, no. 2, pp. 335-345, 1997.

[9] M. D. Paulsgrove and J. W. Wilcut, "Weed management in bromoxynil-resistant Gossypium hirsutum," Weed Science, vol. 47, no. 5, pp. 596-601, 1999.

[10] M. D. Paulsgrove and J. W. Wilcut, "Weed management with pyrithiobac preemergence in bromoxynil-resistant cotton," Weed Science, vol. 49, no. 4, pp. 567-570, 2001.

[11] W. A. Bailey, J. W. Wilcut, and R. M. Hayes, "Weed management, fiber quality, and net returns in no-tillage transgenic and nontransgenic cotton (Gossypium hirsutum)," Weed Technology, vol. 17, no. 1, pp. 117-126, 2003.

[12] D. C. Bridges, T. L. Grey, and B. J. Brecke, "Pyrithiobac and bromoxynil combinations with MSMA for improved weed control in bromoxynil-resistant cotton," Journal of Cotton Science, vol. 6, no. 1, pp. 91-96, 2002.

[13] R. J. Richardson, H. P. Wilson, G. R. Armel, and T. E. Hines, "Mixtures of CGA 362622 and bromoxynil for broadleaf weed control in bromoxynil-resistant cotton (Gossypium hirsutum)," Weed Technology, vol. 17, no. 3, pp. 496-502, 2003.
[14] J. L. Corbett, S. D. Askew, W. E. Thomas, and J. W. Wilcut, "Weed efficacy evaluations for bromoxynil, glufosinate, glyphosate, pyrithiobac, and sulfosate," Weed Technology, vol. 18, no. 2, pp. 443-453, 2004.

[15] G. R. Moran, "4-Hydroxyphenylpyruvate dioxygenase," Archives of Biochemistry and Biophysics, vol. 433, no. 1, pp. 117-128, 2005.

[16] M. H. Schmitt, A. V. Almsick, and L. Willms, "Discovery and chemistry of pyrasulfotole, a new dicot herbicide for cereal production," Pflanzenschutz-Nachrichten Bayer, vol. 61, pp. 714, 2008

[17] M. D. Paulsgrove, D. W. Maruska, K. B. Thorsness, M. C. Smith, G. S. Simkins, and M. Wrucke, "AE, 0317309-a new selective herbicide for dicot weed control in wheat," in Proceedings of the North Central Weed Science Society, vol. 61, p. 107, 2006.

[18] K. B. Thorsness, D. W. Maruska, M. D. Paulsgrove et al., "Introduction to Huskie- A new broadleaf herbicide for use in Northern Plains cereals," in Proceedings of the North Central Weed Science Society, vol. 62, p. 90, 2007.

[19] P. W. Geier and P. W. Stahlman, "Efficacy of pyrasulfotole and bromoxynil tank mixtures in wheat," in Proceedings of the North Central Weed Science Society, vol. 63, p. 4, 2008.

[20] K. K. Watteyne, C. P. Hicks, G. W. Hudec et al., "Weed control in sorghum with Huskie herbicide," in Proceedings of the North Central Weed Science Society, vol. 63, p. 164, 2008.

[21] C. R. Thompson, N. G. Lally, B. L. S. Olson et al., "Pyrasulfotole and bromoxynil, potentially a new herbicide for weed control in grain sorghum," in Proceedings of the North Central Weed Science Society, vol. 64, p. 125, 2009.

[22] R. Brandon and B. Bean, "Evaluation of Huskie herbicide use in grain sorghum," 2012, http://amarillo.tamu.edu/files/2010/ 11/Huskie-Report-USCP.pdf.

[23] National Climatic Data Center, 2012, http://www.ncdc.noaa .gov/oa.ncdc.html.

[24] T. M. Webster, "Weed survey-southern states," in Proceedings of the Southern Weed Science Society, vol. 54, pp. 261-263, 2005.

[25] J. W. Moore and D. S. Murray, "Influence of Palmer amaranth on grain sorghum yields," in Proceedings of the Southern Weed Science Society, vol. 53, pp. 143-144, 2000.

[26] J. L. Shipley and A. F. Wiese, "Economics of weed control in sorghum and wheat," Texas Agricultural Experiment Station Progress Report MP-909, pp. 3-8, 1969. 


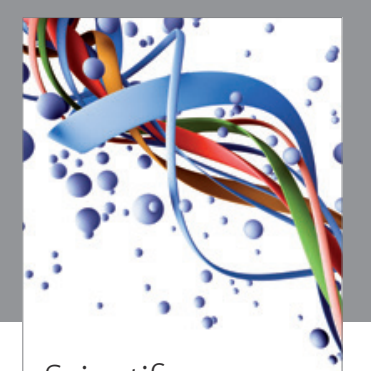

Scientifica
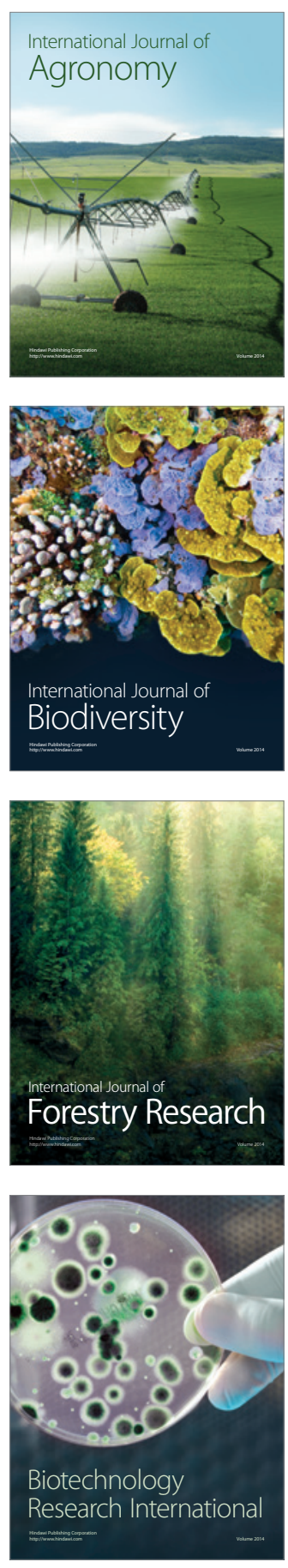
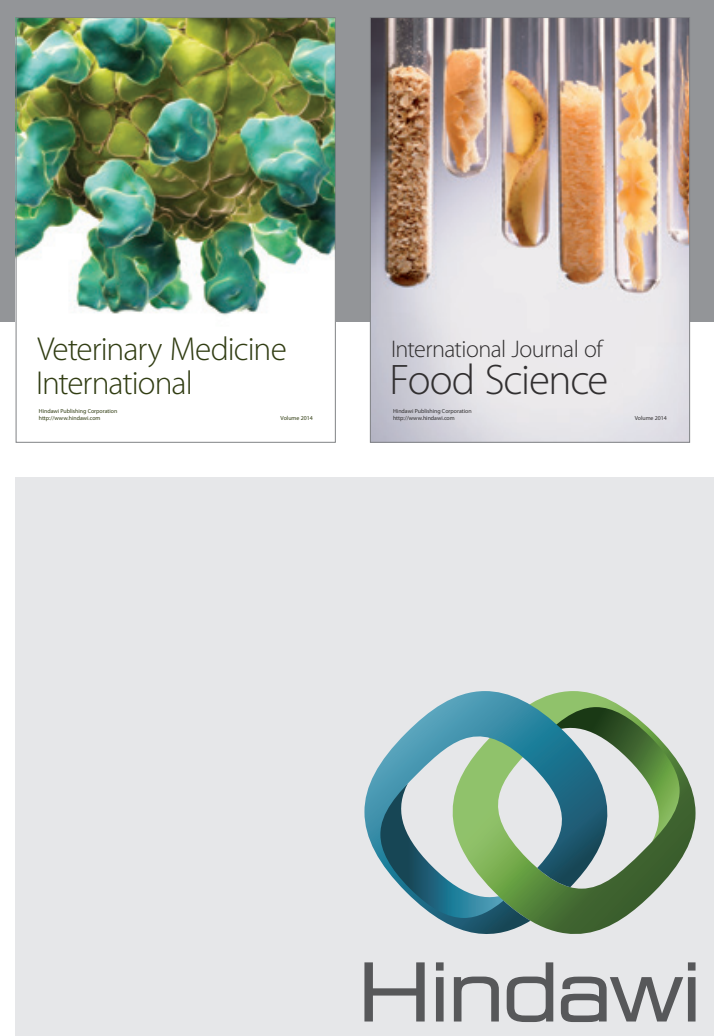

Submit your manuscripts at

http://www.hindawi.com
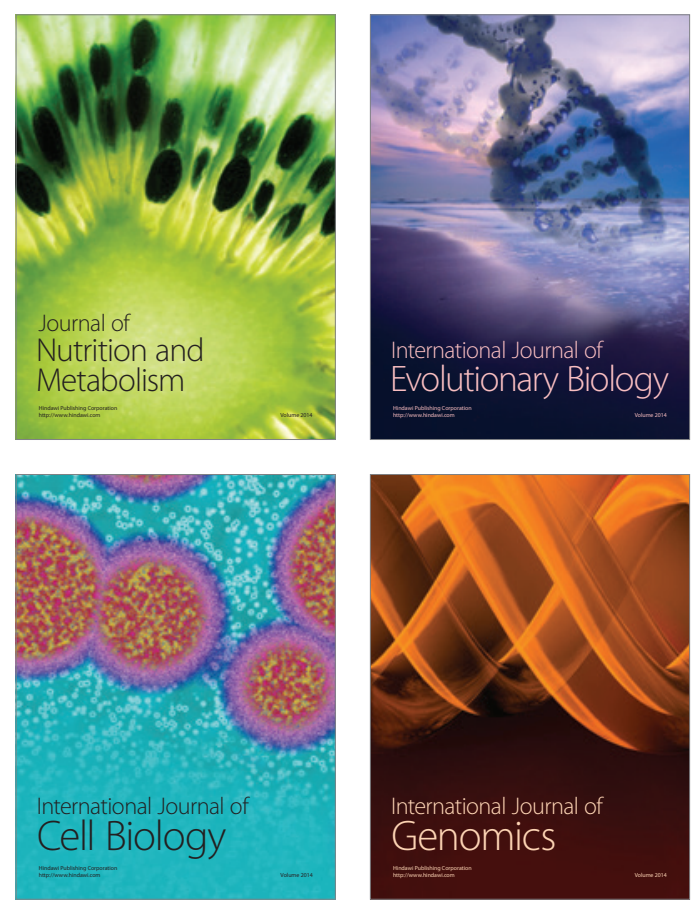
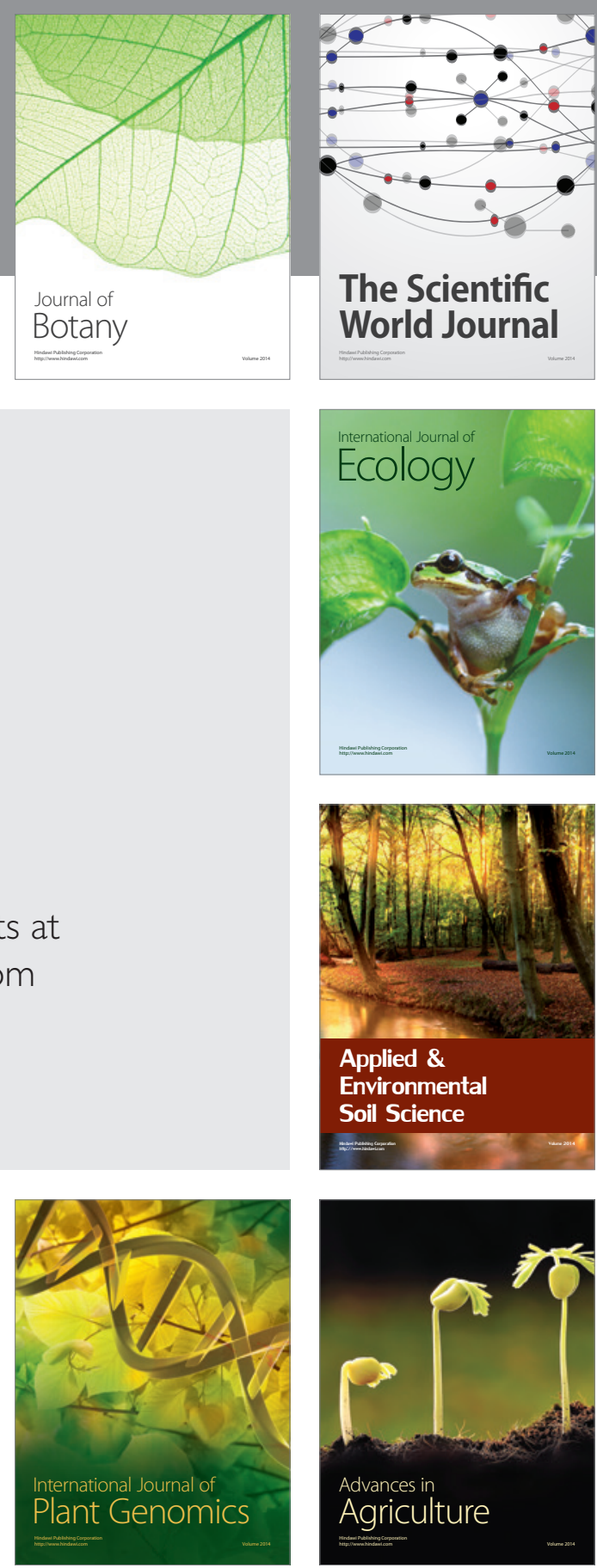

The Scientific World Journal
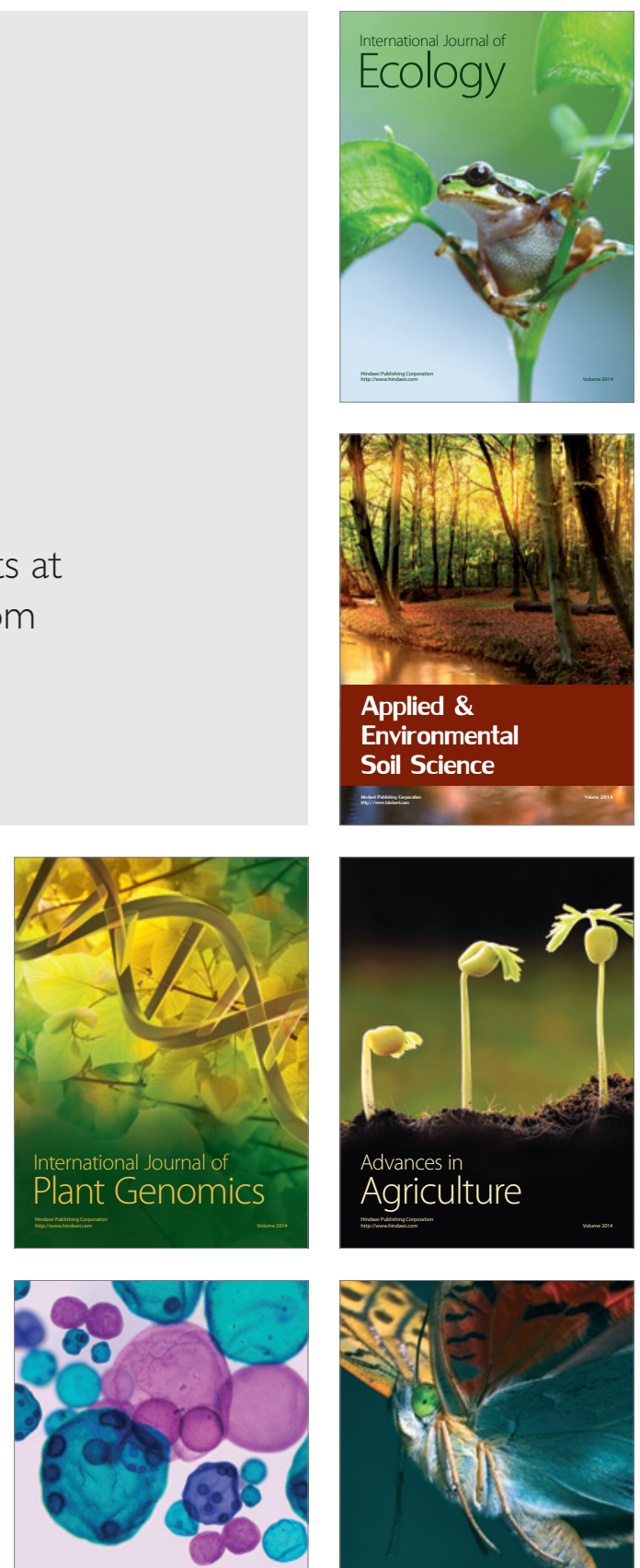

International Journal of Microbiology

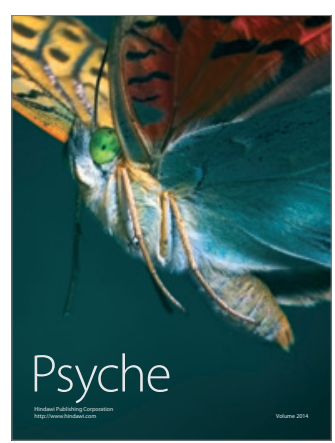

